\title{
Distribution of $\mathrm{Pb}^{2+}$ Ions in $\mathrm{PbF}_{2}$-Doped $\mathrm{CaF}_{2}$ Crystals
}

\author{
M. Paraschiva, I. Nicoara*, M. Stef and O.M. Bunoiu \\ Department of Physics, West University of Timisoara, Bd. V. Parvan 4, Timisoara 300223, Romania
}

(Received May 11, 2009)

\begin{abstract}
Calcium fluoride crystals doped with various concentrations of $\mathrm{PbF}_{2}$ have been grown using the Bridgman technique. The optical absorption spectra reveal the characteristic UV absorption bands of the $\mathrm{Pb}^{2+}$ ions. The distribution of the $\mathrm{Pb}^{2+}$-ions along four crystals has been investigated using the optical absorption method. Taking into account the relationship between the optical absorption coefficient and the concentration of the impurities in the samples, the effective segregation coefficient of the $\mathrm{Pb}^{2+}$ ions has been calculated. Our study shows that the effective segregation coefficient of the $\mathrm{Pb}^{2+}$ ions in $\mathrm{CaF}_{2}$ host depends on the dopant concentration, and varies between 0.85 and 1.15 , for $0.5 \mathrm{~mol} \% \mathrm{PbF}_{2}$ and $3 \mathrm{~mol} \% \mathrm{PbF}_{2}$-doped $\mathrm{CaF}_{2}$, respectively.
\end{abstract}

PACS numbers: 42.70.Hj, 68.35.Dv, 78.20.Ci, 78.40.Ha, 81.10.Fq

\section{Introduction}

The study of optical properties of $n s^{2}$ ions in alkaline halide crystals is an old, well-studied domain [1]. There are few reports on optical properties of these ions in alkaline-earth fluorides; among the $n s^{2}$ ions, the $\mathrm{Pb}^{2+}$ ions are less investigated. Oboth et al. [2] studied the absorption and emission properties of $\mathrm{Pb}: \mathrm{CaF}_{2}$ crystals in vacuum UV spectral range. Various impurity-related color centers in alkaline-earth fluorides have been studied because these centers are laser-active in near IR. For example, the $\mathrm{Pb}^{+}(1)$ centers in alkaline-earth fluorides have analogous properties to $\mathrm{Tl}^{0}(1)$ center in alkali halides and are expected to act as laser-active centers $[3,4]$. Babin et al. [5] studied the influence of $\mathrm{Pb}^{2+}$ ions on the emission properties of the LuAg:Ce single crystalline films and $\mathrm{Su}[6]$ on the optical properties of the $\mathrm{U}: \mathrm{CaF}_{2}$ crystals. The homogeneous dopant distribution in the laser materials is important because this affects the efficiency of the laser. There are a few reported results about the $\mathrm{Pb}^{2+}$ ions distribution in various crystals or on the segregation coefficient determination. Dmitriev [7] studied the influence of the $\mathrm{Pb}^{2+}$ ions on the optical properties of the $\mathrm{TlBr}$ crystal and determined the segregation coefficient; the reported values are 1.3-1.6. The distribution of trace amounts of metal impurities in $\mathrm{CaF}_{2}$ crystals grown by the Bridgman method has been investigated by Yonezawa et al. [8]. They studied the distribution of both metal-fluoride and metal-oxide impurities in $\mathrm{CaF}_{2}$ crystals obtained from highly pure fluoride powder. From their study it can be concluded that $\mathrm{Li}, \mathrm{Na}$ and $\mathrm{Pb}$ hardly remain in $\mathrm{CaF}_{2}$ crystals and the segregation coefficient

* corresponding author; e-mail: nicoara@physics.uvt.ro is $\approx 1$. The effective segregation coefficient of the $\mathrm{Pb}^{2+}$ ions in $\mathrm{CaF}_{2}$ crystal was not reported yet.

The aim of this paper is to investigate the influence of $\mathrm{PbF}_{2}$ content on optical properties of the $\mathrm{CaF}_{2}$ crystals and to determine the effective segregation coefficient using the optical absorption method.

\section{Experimental}

Pure and $\mathrm{PbF}_{2}$-doped $\mathrm{CaF}_{2}$ crystals were grown in our crystal research laboratory using vertical Bridgman method. Suprapure grade (Merck) calcium fluoride and $\mathrm{PbF}_{2}$ were used as the starting materials. It is known [8] that $\mathrm{Pb}^{2+}$ ions hardly remain in fluoride crystals if the usual Bridgman type technique is used for the growth of $\mathrm{CaF}_{2}$ crystals. In order to obtain $\mathrm{PbF}_{2}$-doped $\mathrm{CaF}_{2}$ crystals the following procedure was used. First, pure, oxygen-free $\mathrm{CaF}_{2}$ crystals were grown using the usual growth conditions, namely adding to the starting material an amount of $4 \mathrm{wt} \% \mathrm{PbF}_{2}$ as oxygen scavenger $[9,10]$. The obtained $\mathrm{CaF}_{2}$ crystals do not contain any undesired amount of lead ions or other impurities, as results from the optical absorption spectrum; then the $\mathrm{PbF}_{2}$-doped crystals were grown from the crushed pure fluoride crystals doped with the desired amount of $\mathrm{PbF}_{2}$. To prevent the evaporation of the $\mathrm{PbF}_{2}$, a thin floating graphite lid was put on the charge in a sealed graphite crucible. In this work, four $\mathrm{PbF}_{2}$-doped crystals have been investigated with the following amount of $\mathrm{PbF}_{2}$ added in the starting mixture in the melt: $0.5,1,2$, and $3 \mathrm{~mol} \% \mathrm{PbF}_{2}$. Transparent colorless crystals of about $10 \mathrm{~mm}$ in diameter over 6-7 cm long were obtained in spectral pure graphite crucible in vacuum $\left(\approx 10^{-1} \mathrm{~Pa}\right)$ using a shaped graphite furnace [11]. The pulling rate was $4 \mathrm{~mm} / \mathrm{h}$. The crystals were cooled to room temperature using an estab- 


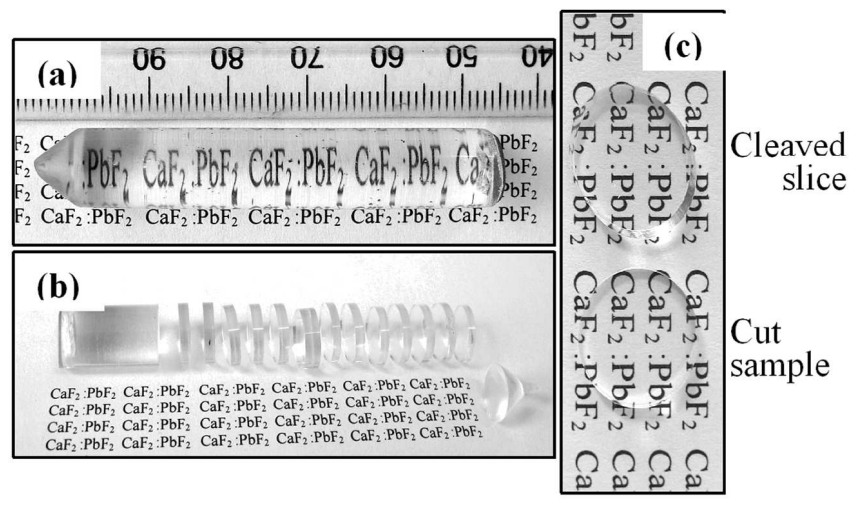

Fig. 1. As-grown $x$ mol\% $\mathrm{PbF}_{2}$-doped $\mathrm{CaF}_{2}$ crystals: (a) $x=2$; (b) crystal cut for the distribution coefficient measurements, $x=1$; (c) 1 mol\% $\mathrm{PbF}_{2}$ doped $\mathrm{CaF}_{2}$ crystal-cleaved slice and $x=0.5$ cut sample.

lished procedure. The as-grown single crystals are shown in Fig. 1.

The effective segregation coefficient, $k_{\text {eff }}$, has been determined using the optical absorption method [12-14]. In order to investigate the dopant concentration along the crystals and to determine the distribution coefficient, the crystals were cut from the bottom to the top into $i=14-15$ slices (Fig. 1b). Each wafer was about $2 \mathrm{~mm}$ in thickness, and optically polished. The absorption coefficient $\alpha(i)$ of every slice was calculated from the absorption spectra for the well-shaped and strong characteristic absorption band of the $\mathrm{Pb}^{2+}$ ions, namely for $A=306 \mathrm{~nm}$ band. Taking into account the BeerLambert law, the absorption coefficient is proportional to the concentration, so the dopant distribution along the crystal can be estimated. The segregation coefficient for various $\mathrm{PbF}_{2}$ concentrations in $\mathrm{CaF}_{2}$ crystals was then calculated using a procedure described in Sect. 3.2. Room temperature optical absorption spectra were recorded by a Shimadzu $1650 \mathrm{PC}$ spectrophotometer.

\section{Results and discussions}

$\mathrm{CaF}_{2}$ crystallizes in cubic structure with a typical fluorite lattice. In order to understand the optical properties and the dopant distribution in $\mathrm{CaF}_{2}$ crystals it is better to see this structure as consisting of a simple cubic lattice of fluorine ions in which every other body center position is occupied by a $\mathrm{Ca}^{2+}$ ion. When various ions, such as alkaline metals, rare-earths or heavy metal ions, like $\mathrm{Pb}^{2+}$ are introduced into the lattice they usually occupy $\mathrm{Ca}^{2+}$ sites. If the introduced impurity ions have other valence than the $\mathrm{Ca}^{2+}$ ion, the valence mismatch is compensated in a variety of ways: by vacancy formation, by interstitial fluorine ion, etc. The $\mathrm{Pb}^{2+}$ ion has the same valence as $\mathrm{Ca}^{2+}$ but with a larger geometric size $(0.143 \mathrm{~nm})$ than the $\mathrm{Ca}^{2+}$ ion $(0.126 \mathrm{~nm})$, and for high dopant concentrations this will lead to distortion of the crystal lattice; this is the reason why the crystals doped with more than $3 \mathrm{~mol} \% \mathrm{PbF}_{2}$ reveal structural defects, like blocks with different crystallographic orientations.

\subsection{Optical absorption spectra}

The presence of impurity ions in $\mathrm{CaF}_{2}$ lattice with the $n s^{2}$ ground state configuration (like $\mathrm{Pb}^{2+}$ ions) induces absorption bands both in vacuum ultraviolet (VUV) and in UV domain $[1,2]$. Four characteristic bands are located in UV domain, denoted by A, B, C, and D [1].

The absorption spectra of various concentrations $\mathrm{CaF}_{2}: \mathrm{PbF}_{2}$ samples reveal the four characteristic absorption bands of $\mathrm{Pb}^{2+}$ ions (Fig. 2).

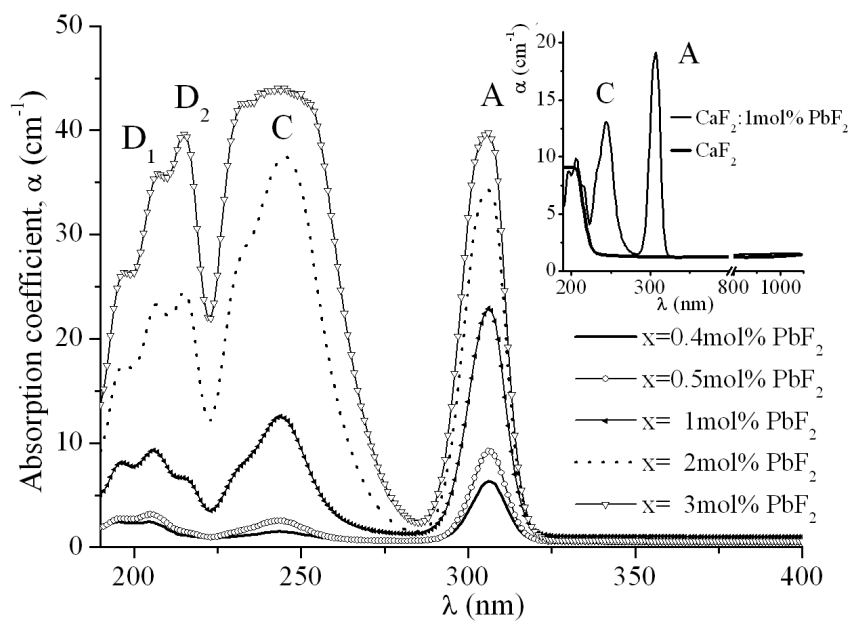

Fig. 2. Room temperature absorption spectra of $\mathrm{PbF}_{2}$ doped $\mathrm{CaF}_{2}$ crystals. The inset shows the absorption spectra of pure and $1 \mathrm{~mol} \% \mathrm{PbF}_{2}$-doped $\mathrm{CaF}_{2}$ crystals.

$\mathrm{As} \mathrm{Pb}^{2+}$-ions concentration increases, the shape of the $\mathrm{C}$ and $\mathrm{D}$ absorption bands modifies due to the overlap of many new bands that appear as a result of the energy levels splitting. Only the A band conserves ir sharp shape because no new components appear. This is the peak which we will use for the effective segregation coefficient determination by optical absorption method. The $\mathrm{B}$ band is observed only in the excitation spectra obtained for various bands of the emission spectra. For low concentrations $\left(0.4\right.$ and $\left.0.5 \mathrm{~mol} \% \mathrm{PbF}_{2}\right)$ only three peaks appear in the absorption spectrum: $\mathrm{A}=306.2 \mathrm{~nm}$, $\mathrm{C}=243.1 \mathrm{~nm}$ and $\mathrm{D}=203.7 \mathrm{~nm}$; the $\mathrm{A}$ band is the strongest. For $1 \mathrm{~mol} \%$ the following peaks are characteristic: $\mathrm{A}=306.1 \mathrm{~nm}$, the $\mathrm{C}$ band peaking at $244 \mathrm{~nm}$ for low concentration consists now of two overlapping bands peaking at 228 and $246 \mathrm{~nm}$, as results from the excitation spectrum; the $\mathrm{D}$ band also splits into two bands: $D_{1}=214$ and $D_{2}=206 \mathrm{~nm}$. As the concentration increases, the peaks position are shifted to: $\mathrm{A}=305.4 \mathrm{~nm}, \mathrm{C}=244$ and $246 \mathrm{~nm}$ and a shoulder at $228 \mathrm{~nm}, \mathrm{D}_{1,2}=215$ and $206.8 \mathrm{~nm}$ for $2 \mathrm{~mol} \% \mathrm{PbF}_{2}$. For $3 \mathrm{~mol} \% \mathrm{PbF}_{2}$ sample the absorption bands are: $\mathrm{A}=$ $305.4 \mathrm{~nm}, \mathrm{C}$ band becomes very broad as a result of an in- 
crease in intensity of more than three overlapping components, and $\mathrm{D}_{1}=215, \mathrm{D}_{2}=207.5 \mathrm{~nm}$. The intensity ratio of the $\mathrm{D}$ band components differs for the samples with concentration $\geq 1 \mathrm{~mol} \% \mathrm{PbF}_{2}$ : the $\mathrm{D}_{2}$ increases more than the $\mathrm{D}_{1}$ component. The intensity of the $\mathrm{D}$ and $\mathrm{C}$ bands increases as the concentration increases and becomes comparable with the intensity of the A band.

Figure 3 shows the influence of the $\mathrm{Pb}^{2+}$ ions concentration $\left(N_{0}\right)$ in the initial melt on the absorption coefficient of the A peak; the absorption coefficient was calculated for slices cut from the same position for every crystal. $N_{0}$ is the number of the $\mathrm{Pb}^{2+}$ ions per unit volume in $\mathrm{PbF}_{2}$ doped $\mathrm{CaF}_{2}$ crystals, calculated using the expression

$$
N_{0}=\rho \frac{C_{\mathrm{L}}^{0} N_{\mathrm{A}}}{\mu},
$$

where $\rho$ is the crystal density, $C_{\mathrm{L}}^{0}$ is the dopant concentration (mol\%) in the initial melt, $N_{\mathrm{A}}$ is Avogadro's number and $\mu$ is the molecular mass.

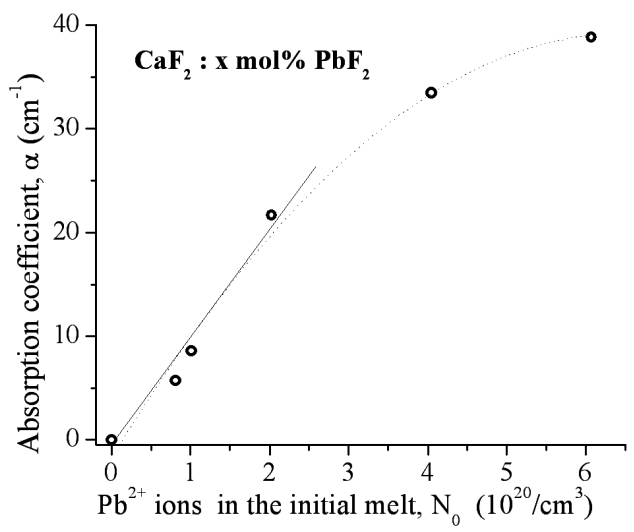

Fig. 3. Dependence of the absorption coefficient on the $\mathrm{Pb}^{2+}$ ions concentration $\left(N_{0}\right)$ in the initial melt (measured for A band).

As the concentration increases, the absorption coefficient increases linearly for the first three concentrations: $0.4,0.5$ and $1 \mathrm{~mol} \% \mathrm{PbF}_{2}$ (see Fig. 3), then a saturation behavior appears. The A peak shape, namely the absorption coefficient and the FWHM (the peak half-width), changes as the $\mathrm{PbF}_{2}$ concentration increases, but no new components appear for this absorption band in comparison with $\mathrm{C}$ or $\mathrm{D}$ bands (see Fig. 2).

For a given $\mathrm{PbF}_{2}$ concentration, the FWHM of the A peak is the same for the various slices cut along the crystal, only the absorption coefficient, $\alpha_{i}$, varies from slice to slice, as is shown in Fig. 4. This behavior is used for the effective segregation coefficient determination by optical absorption method [12, 13].

The alkali halide crystals doped with ions which have the $n s^{2}$ electronic configuration in their ground state have been studied more extensively [1] than the alkaline-earth fluorides. The presence of this type impurity ion induces from three to six absorption bands in UV do-

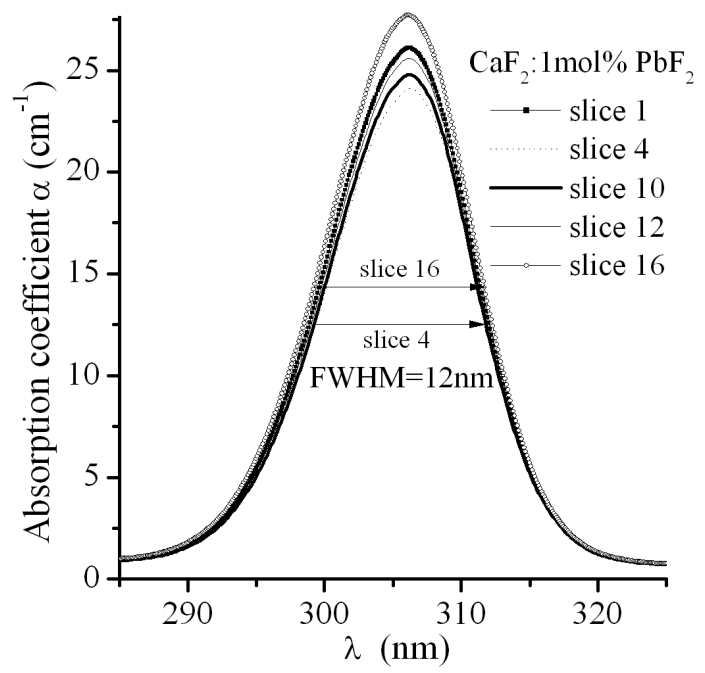

Fig. 4. The A band of various slices cut from $1 \mathrm{~mol} \% \mathrm{PbF}_{2}$ doped $\mathrm{CaF}_{2}$ crystal.

main. Oboth et al. [2] studied the absorption and emission spectra of $\mathrm{Pb}^{2+}$ centers in alkaline-earth fluorides in VUV domain, their A denoted absorption band corresponds to our D band.

The optical absorption bands are assigned to electronic transitions from the $\left(6 s^{2}\right)$ ground state to the $\left(6 s^{1}\right)\left(6 p^{1}\right)$ excited state: A $\left({ }^{1} S_{0}-{ }^{3} P_{1}\right.$, spin orbit allowed $)$, B $\left({ }^{1} S_{0}-{ }^{3} P_{2}\right.$ vibrationally allowed), and $\mathrm{C}\left({ }^{1} S_{0}-{ }^{1} P_{1}\right.$ dipole allowed).

\subsection{Determination of the effective segregation coefficient of $\mathrm{Pb}^{2+}$ ions}

The effective segregation coefficient $\left(k_{\text {eff }}\right)$ at a given growth rate is defined by

$$
k_{\mathrm{eff}}=C_{\mathrm{S}} / C_{\mathrm{L}}^{0}
$$

where $C_{\mathrm{S}}$ is the dopant concentration at the bottom of the as-grown crystal and $C_{\mathrm{L}}^{0}$ is the dopant concentration in the initial melt. The value of $C_{\mathrm{S}}$ can be measured by various methods, or estimated from optical absorption measurements [12-14].

The effective segregation coefficient determination of the $\mathrm{Pb}^{2+}$ ions in $\mathrm{CaF}_{2}$ host by optical absorption method is based on the following two laws.

(a) According to the Beer-Lambert law the absorption coefficient is proportional to the sample concentration $(C), \alpha=a C$, where $a$ is the absorption coefficient for unit $\mathrm{Pb}$ concentration and unit light path length; $a$ may be recognized as constant for the investigated $\mathrm{Pb}^{2+}$ ions concentration [12-14]. The $\mathrm{Pb}^{2+}$ ions concentration can be estimated from the measured optical density, O.D. $=\log \left(I_{0} R / I\right)$, where $I_{0}$ is the light intensity incident on the sample, $R$ is the the reflection factor on sample surface, $I$ is the transmitted light intensity [13]. Taking into account the relation

$$
I=I_{0} R \exp (-\alpha d),
$$

where $\alpha$ is the absorption coefficient and $d$ is the sample 
thickness, the dopant concentration of a slice can be estimated using the relation [13]:

$$
C=\frac{\alpha}{a}=\frac{2.30258 \text { O.D. }}{a d} \text {. }
$$

(b) The dopant concentration (along the growth axis) at the distance $z$ from the origin of the crystal can be obtained by using the classical relation [15]:

$$
C_{\mathrm{S}}(z)=C_{\mathrm{L}}^{0} k_{\mathrm{eff}}[1-g(z)]^{k_{\mathrm{eff}}-1},
$$

where $g(z)$ is the crystallized fraction of the melt given by $g(z)=V_{p} t / L=z / L, V_{p}$ is the crystal growth rate, $t$ is the growth time and $L$ is the crystal length, so $V_{p} t$ is the grown crystal length, $z$, at the moment $t$. The more the $k_{\text {eff }}$ differs from unity, the larger is the concentration gradient in the crystal.

Therefore, taking into account the Beer-Lambert law, the dopant distribution along the crystal length can be estimated using the optical absorption method. In order to determine the effective segregation coefficient, we cut the crystal into $i$ slices with the same thickness (Fig. 1b) and calculate the absorption coefficient for the absorption peak at $306 \mathrm{~nm}$, from the optical absorption spectrum of every slices $(\alpha(z))$. Using the relations (4) and (5), the following expression is obtained in order to determine the effective segregation coefficient:

$$
\log \alpha(z)=\left(k_{\mathrm{eff}}-1\right) \log (1-z / L)+\log \left(a k_{\mathrm{eff}} C_{\mathrm{L}}^{0}\right) .
$$

The effective segregation coefficient can be calculated from the slope $m=k_{\text {eff }}-1$, of the fitting line of $\log \alpha(z)$ versus $\log (1-z / L)$.

Figure 5 shows the $\mathrm{Pb}^{2+}$ ions distribution (characterized by the absorption coefficient) along the four investigated crystals, with various $\mathrm{PbF}_{2}$ concentrations in the initial melt. The dopant distribution along the crystals shows some oscillations of the $\mathrm{Pb}^{2+}$-ions concentration. These types of oscillations have been also observed for other crystals grown by the Bridgman technique; this behavior has not been explained yet $[16,17]$. For concentrations $\leq 1 \mathrm{~mol} \%$ the absorption coefficient increases along the crystals and consequently, the concentration increases, too. For $\mathrm{CaF}_{2}: 2 \mathrm{~mol} \% \mathrm{PbF}_{2}$ sample the dopant distribution along the crystal has the strongest oscillatory behavior; for the $3 \mathrm{~mol} \% \mathrm{PbF}_{2}-\mathrm{CaF}_{2}$ sample the absorption coefficient decreases along the crystal (the concentration also decreases).

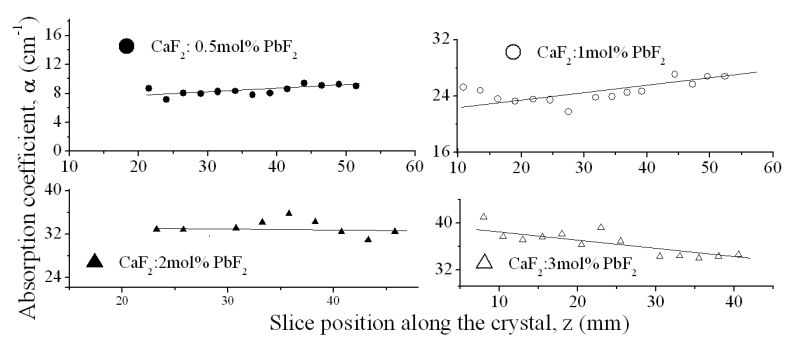

Fig. 5. $\mathrm{Pb}^{2+}$ ions distribution along the crystals characterized by the absorption coefficient; the $\mathrm{PbF}_{2}$ concentration in the initial melt is indicated in the figure.
TABLE

Effective segregation coefficient.

\begin{tabular}{c|c|c|c|c}
\hline \hline $\mathrm{CaF}_{2}: x \mathrm{~mol}^{2} \mathrm{PbF}_{2}$ & $x=0.5$ & $x=1$ & $x=2$ & $x=3$ \\
\hline$k_{\text {eff }}$ & 0.85 & 0.925 & 1.002 & 1.15
\end{tabular}

The calculated effective segregation coefficient for the studied samples is shown in Figs. 6, 7 and Table. As the concentration of the $\mathrm{Pb}^{2+}$ ions in the initial melt increases, the effective segregation coefficient, $k_{\text {eff }}$, increases, too. The obtained values are: 0.85 for $\mathrm{CaF}_{2}: 0.5 \mathrm{~mol} \% \mathrm{PbF}_{2}$ crystal, 0.925 for $\mathrm{CaF}_{2}: 1 \mathrm{~mol} \% \mathrm{PbF}_{2}$ crystal, 1.002 for $\mathrm{CaF}_{2}: 2 \mathrm{~mol} \% \mathrm{PbF}_{2}$ crystal and 1.15 for $\mathrm{CaF}_{2}: 3 \mathrm{~mol} \% \mathrm{PbF}_{2}$ crystal.

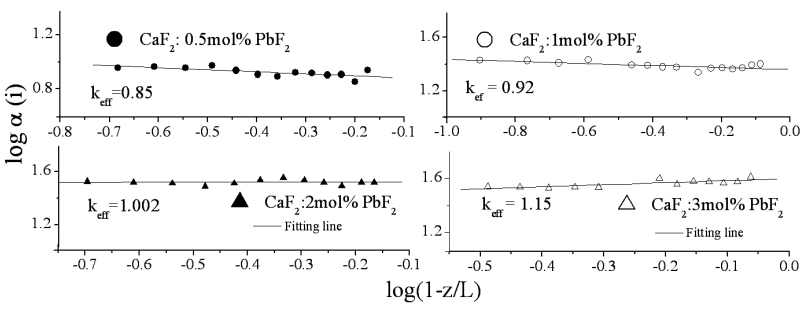

Fig. 6. Fitting lines of $\log \alpha(z)$ vs. $\log (1-g)$ in order to calculate the effective segregation coefficient; the obtained $k$ values are indicated in the figures.

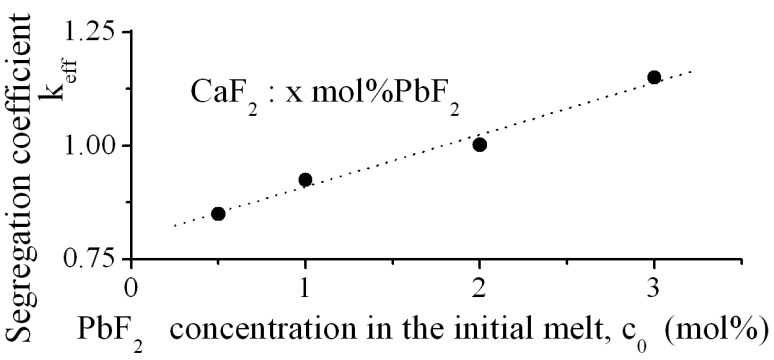

Fig. 7. Dependence of the effective segregation coefficient of $\mathrm{Pb}^{2+}$ ions in $\mathrm{CaF}_{2}$ on the $\mathrm{PbF}_{2}$ concentration in the initial melt.

Preliminary luminescence studies reveal a strong emission spectrum in the near UV domain (at $323 \mathrm{~nm}$ and $341 \mathrm{~nm}$ ) and in the visible region (at $644 \mathrm{~nm}$ ). The strongest emission has been obtained for $\mathrm{CaF}_{2}: 2 \mathrm{~mol} \% \mathrm{PbF}_{2}$ probe. Because the effective segregation coefficients are almost equal to unity, the $\mathrm{Pb}^{2+}$-ions distribution in $\mathrm{CaF}_{2}$ crystals is approximately uniform and from this point of view, $\mathrm{PbF}_{2}$-doped $\mathrm{CaF}_{2}$ crystals could be a good laser material in near UV domain.

\section{Conclusions}

Various $\mathrm{PbF}_{2}$ concentrations doped $\mathrm{CaF}_{2}$ crystals were grown using the conventional Bridgman technique. In 
order to prevent the $\mathrm{PbF}_{2}$ evaporation a special crystal growth procedure was adopted. The absorption spectra reveal the characteristic absorption bands of the $\mathrm{Pb}^{2+}$ ions. A strong concentration dependence of the absorption spectra has been observed. The effective segregation coefficient of the $\mathrm{Pb}^{2+}$ ions in $\mathrm{CaF}_{2}$ host has been determined using the optical absorption method. The segregation coefficient of $\mathrm{Pb}^{2+}$ ions in $\mathrm{CaF}_{2}$ has not been reported before.

\section{Acknowledgments}

This work was supported by the Science Research Council, Romania, grant CEEX no. 72/2006.

\section{References}

[1] P.W.M. Jacobs, J. Phys. Chem. Solids 52, 35 (1991).

[2] K.P. Oboth, F.J. Lohmeller, F. Fischer, Phys. Status Solidi B 154, 789 (1989).

[3] M. Fockele, F. Lohse, J.-M. Spaeth, R.H. Bartram, J. Phys., Condens. Matter 1, 13 (1989).

[4] R.H. Bartram, M. Fockele, F. Lohse, J.-M. Spaeth, J. Phys., Condens. Matter 1, 27 (1989).

[5] V. Babin, V. Gorbenko, A. Makhov, M. Nikl, S. Zazubovich, Y. Zorenko, Phys. Status Solidi C 4, 797 (2007).
[6] L. Su, W. Yang, J. Xu, Y. Doung, G. Zhou, J. Cryst. Growth 270, 150 (2004).

[7] Y. Dmitriev, P.R. Bennett, L.J. Cirignano, T.K. Gupta, W.M. Higgins, K.S. Shah, P. Wong, Nucl. Instrum. Methods Phys. Res. A 578, 510 (2007).

[8] T. Yonezawa, J. Nakayama, K. Tsukuma, Y. Kawamoto, J. Cryst. Growth 244, 63 (2002).

[9] D.C. Stockbarger, J. Opt. Soc. Am. 39, 731 (1949).

[10] A. Molchanov, J. Friedrich, G. Wehrhan, G. Muller, J. Cryst. Growth 273, 629 (2005).

[11] D. Nicoara, I. Nicoara, Mater. Sci. Eng. A 102, L1 (1988).

[12] K. Shiroki, Y. Kwan, J. Chem. Soc. Japan 7, 940 (1978).

[13] Y. Kuwano, J. Cryst. Growth 57, 353 (1982).

[14] D. Sun, Q. Zhang, Z. Wang, J. Su, C. Go, A. Wang, S. Yin, Cryst. Res. Technol. 40, 698 (2005).

[15] D.T. Hurle, Crystal Pulling from the Melt, Springer-Verlag, Berlin 1993.

[16] C. Barat, Ph.D. Thesis, University of Rennes, 1995.

[17] A. Mitric, T. Duffar, C. Diaz-Guerra, V. Corregidor, L.C. Alves, C. Garnier, G. Vian, J. Cryst. Growth 287, 224 (2006). 